NOTA TÉCNICA

\title{
Cultivos primarios de células endoteliales aisladas de cordón umbilical humano: un modelo biológico para el estudio de los mecanismos de infección por enterococos
}

\author{
Carlos Andrés Chiriboga ${ }^{1}$, Marta Raquel Fontanilla ${ }^{2}$ \\ ${ }^{1}$ Laboratorio de Biología Molecular, Universidad El Bosque; programa de posgrado interfacultades de \\ Microbiología, Universidad Nacional de Colombia, Bogotá, D.C., Colombia. \\ ${ }^{2}$ Instituto de Biología Molecular, Universidad El Bosque; Departamento de Farmacia, Facultad de Ciencias, \\ Universidad Nacional de Colombia, Bogotá, D.C., Colombia.
}

Aunque las especies de enterococos son flora normal del tracto gastrointestinal humano, se encuentran entre los tres agentes patógenos microbianos que más se asocian con infecciones intrahospitalarias. Tradicionalmente, los enterococos se han considerado bacterias extracelulares. Sin embargo, es creciente la información que reporta su ingreso a través de líneas celulares epiteliales o macrófagos. A pesar de que estos microorganismos constituyen el tercer grupo de aislamientos obtenido de pacientes con bacteriemia o endocarditis, su interacción con la célula endotelial no se ha descrito completamente. En el presente trabajo evaluamos si el aislamiento intrahospitalario de Enterococcus faecalis (Ef2880) podía penetrar en células endoteliales de la vena de cordón umbilical humano (HUVEC) cultivadas in vitro. Nuestros resultados indican que los cultivos primarios HUVEC después de ser inoculados con Ef2890, incubados y tratados con antibióticos bactericidas para las bacterias extracelulares y adheridas a la cara externa de la membrana celular, exhiben bacterias intracelulares que pueden ser recuperadas vivas cuatro horas después de la inoculación. El modelo biológico desarrollado se puede constituir en una herramienta útil para el estudio de las interacciones que establecen los enterococos con el endotelio.

Palabras clave: endotelio, cultivo celular, Enterococcus sp., infección enterocócica de cultivos de HUVEC

Primary cultures of human umbilical chord vein endothelial cells: a biological model for studying enterococcal infection mechanisms

Although enterococcus bacteria are normal human intestinal flora, they rank as the third most common pathogen involved in hospital acquired infections. Generally, these bacteria are considered extracellular pathogens; however, an increasing number of reports indicate invasiveness to epithelial cell lines and macrophages. Despite their importance as nosocomial infection agents in patients suffering bacteremias and endocarditis, their interaction with endothelial cells has not been fully described. Herein, the nosocomial Enterococcus faecalis isolate Ef2890 from a hospitalized patient was exposed to cultured human venous endothelial cells from the umbilical chord. When the primary cell cultures were inoculated with Ef2890 and treated with bactericidal antibiotics to kill extracellular and adhered bacteria, intracellular bacteria were recovered and plated $4 \mathrm{~h}$ post-infection. These observations indicate that cell cultures provide a valuable biological model to study interactions between endothelium and enterococci.

Key words: Enterococcus sp., endothelium, cell culture, enterococcal infection, nosocomial infections. 
Los enterococos son parte de la flora normal del tracto gastrointestinal humano. Sin embargo, las bacterias de este género son aislamientos de nosocomios, principalmente de pacientes con endocarditis, bacteriemias e infecciones urinarias (1-3). Lo anterior se ve agravado por el incremento, incluso en Colombia, del número de aislamientos resistentes a los antibióticos comúnmente empleados en el tratamiento de estas infecciones $(4,5)$.

La endocarditis infecciosa es una patología del endotelio que afecta generalmente las válvulas normales, protésicas o patológicas del corazón (6). La lesión característica, denominada "vegetación", es una biopelícula que se forma cuando las bacterias circulantes se adhieren al endotelio lesionado y son cubiertas por una capa de plaquetas y fibrina. El microambiente proporcionado por la biopelícula esconde el microorganismo, y le permite evitar la acción defensiva del sistema inmune y sobrevivir (6).

Los estudios con bacterias Gram negativas y Gram positivas han mostrado su efecto regulador o de sus productos sobre la expresión por parte de las células endoteliales de moléculas de adhesión, factores de crecimiento y citocinas endoteliales en las infecciones sistémicas (7-11). Sin embargo, la investigación sobre los procesos de penetración de cepas de enterococos en células endoteliales no está muy desarrollada, en parte, porque estos organismos se consideran flora normal (3).

La emergencia de enterococos con niveles importantes de resistencia a los antibióticos ha hecho que aumente el interés por entender los mecanismos que estas bacterias usan para lesionar los tejidos de los sitios que colonizan. Ya se ha demostrado que las cepas de Enterococcus faecalis resistentes a los antibióticos son capaces de trasladarse a través del epitelio intestinal de ratones $(12,13)$ y los estudios sobre los factores bacterianos

Correspondencia:

Marta Raquel Fontanilla, Calle 52 B No 4-34, email: mrfontani@yahoo.com

Recibido: 01/06/04; aceptado: 13/09/04 involucrados en las interacciones célula-patógeno han identificado sustancias que desempeñan un papel importante en el ingreso de la bacteria en enterocitos y macrófagos cultivados (14-16). Como se cree que muchas infecciones enterocócicas del torrente sanguíneo tienen origen entérico (17), los estudios in vitro se han enfocado a entender los mecanismos empleados por los enterococos para superar la barrera epitelial y sobrevivir en los macrófagos. Recientemente, se reportó que los aislamientos nosocomiales de $E$. faecalis se adhieren e invaden células HeLa y que la endocitosis mediada por receptores puede ser uno de los mecanismos utilizados por la bacteria para invadir este tipo de célula epitelial (17).

A pesar de que en las vegetaciones características de la endocarditis los enterococos interactúan estrechamente con las células endoteliales, in vitro no se ha estudiado la relación que establecen las diferentes especies enterocócicas con las células endoteliales. Tampoco, si estas células en cultivo introducen enterococos ni el papel que este proceso puede jugar en la recurrencia de la infección.

El propósito de este trabajo fue establecer si un aislamiento intrahospitalario de enterococo, inoculado en cultivos primarios de células endoteliales aisladas de la vena del cordón umbilical humano (HUVEC) es capaz de invadir las células endoteliales. Con este fin, estandarizamos los procedimientos que se deben seguir para infectar cultivos HUVEC con aislamientos nosocomiales de E. faecalis. Encontramos que al exponer las células a las bacterias por dos horas y luego tratarlas con antibióticos para eliminar $E$. faecalis extracelulares o adheridos a la membrana, es posible encontrar bacterias en el interior de las HUVEC cultivadas.

\section{Materiales y métodos}

\section{Aislamientos bacterianos y sus condiciones de cultivo}

Para este trabajo se utilizó el aislamiento clínico E. faecalis Ef 2890. La caracterización y los patrones de susceptibilidad antimicrobiana de este 
aislamiento se describieron previamente por el Instituto de Genética Molecular Bacteriana de la Universidad El Bosque (4). La cepa no invasiva Escherichia coli DH5a sirvió como control negativo en los experimentos de infección. Las bacterias se mantuvieron y crecieron en caldo o agar infusión cerebro-corazón (BHI) (Biomedics, Madrid, España). Para preparar los inóculos utilizados en la infección, se inocularon suspensiones de los aislamientos en agar $\mathrm{BHI}$ y se incubaron a $35^{\circ} \mathrm{C}$ por 24 horas. Luego de la incubación, se resuspendieron 4 o 5 colonias en $20 \mathrm{ml}$ de caldo $\mathrm{BHI}$ y se incubaron a $35^{\circ} \mathrm{C}$ por 18 horas con agitación constante a $150 \mathrm{rpm}$ en un baño de María (Shaker Bath, Lab-line, USA). Posteriormente, se tomó $1 \mathrm{ml}$ de este cultivo, se resuspendió en $9 \mathrm{ml}$ de medio RPMI (Gibco, Invitrogen Corporation, Grand Island, NY) y se incubó hasta alcanzar una OD625 de 0,08 a 0,1, equivalente a $1 \times 10^{8} \mathrm{UFC} / \mathrm{ml}$, aproximadamente. Los cultivos así obtenidos se utilizaron como inóculos en los ensayos de invasión.

\section{Aislamiento y cultivo de células endoteliales de vena umbilical humana}

Las células endoteliales de vena umbilical humana se obtuvieron siguiendo el protocolo establecido por Beekhuizen et al. (7) con algunas modificaciones introducidas por nosotros. Después de obtener el consentimiento informado firmado por las pacientes, se tomaron segmentos de cordón umbilical de $15 \mathrm{~cm}$, aproximadamente, obtenidos de partos normales en el Servicio de Obstetricia de la Clínica El Bosque. Los segmentos de cordón se transportaron en solución tampón salina de fosfatos (PBS, pH 7,4) con suplemento de penicilina/estreptomicina (100 UI$100 \mathrm{mg}$ ) (GIBCO), se lavaron y se desinfectaron externamente con etanol al $70 \%$.

En los cordones limpios y desinfectados, se localizaron y canularon ambos extremos de la vena umbilical con aguja roma $21 \mathrm{fr}$ y se fijaron las agujas con pinzas de Kelly. La vena umbilical se lavó con PBS para eliminar rastros de sangre, se Ilenó con una solución de tripsina-EDTA $(0,25 \% /$ $0,02 \% \mathrm{p} / \mathrm{v})(\mathrm{GIBCO})$ y se incubó por 15 minutos a $37^{\circ} \mathrm{C}$. Pasado este tiempo, las células endoteliales fueron desprendidas lavando la vena con $10 \mathrm{ml}$, aproximadamente, de medio DMEM (GIBCO) con suplemento de $10 \%$ de suero fetal bovino (SFB) (GIBCO). La suspensión celular obtenida se centrifugó a $1.800 \mathrm{~g}$ por 10 minutos; el sedimento se resuspendió en medio DMEM co suplemento al $20 \%$ de SFB, penicilina-estreptomicina (100 UI$100 \mathrm{mg}$ ), vitaminas (ICN, Biomedicals Inc.), aminoácidos no esenciales (GIBCO, Life Technologies) y piruvato de sodio al $1 \%$ (GIBCO, Life Technologies).

La cantidad de células viables presentes en la suspensión celular obtenida se determinó con una tinción vital (azul de tripano) y se escogieron suspensiones con viabilidades superiores al $80 \%$ para realizar las siembras. El inóculo empleado por frasco $T$ de $12,5 \mathrm{~cm}^{2}$ (Falcon) fueron las células endoteliales aisladas de venas umbilicales de tres segmentos de $10 \mathrm{~cm}$. Los cultivos se incubaron en atmósfera controlada con $5 \%$ de $\mathrm{CO}_{2}$ y temperatura de $37^{\circ} \mathrm{C}$ hasta observar confluencia. Para los ensayos de invasión, se utilizaron cultivos de segundo pasaje.

\section{Caracterización de los cultivos HUVEC primarios mediante detección inmunohistoquímica de la expresión del factor von Willebrand}

La expresión del factor VIII de la coagulación, factor von Willebrand (vW), en los cultivos HUVEC se detectó utilizando como anticuerpo primario un anticuerpo monoclonal de ratón anti-vW humano en dilución 1:25 (Dako, Dinamarca) y como anticuerpo secundario, un anticuerpo policlonal de cabra anti-ratón, conjugado con peroxidasa (Dako, Dinamarca) en dilución 1:100. Para la inmunotinción, se fijó el cultivo con metanol por 5 minutos y la placa sembrada se sometió a la siguiente serie descendente de baños con etanol para deshidratarla: $100 \%$ por 15 minutos, $95 \%$ por 10 minutos y $70 \%$ por 5 minutos. Después de lavar con PBS por 10 minutos, se bloqueó con gelatina al $1 \%$ por 1 hora, se volvió a lavar con PBS, se incubó con $\mathrm{H}_{2} \mathrm{O}_{2}$ por 5 minutos y se lavó con PBS. Se agregó el anticuerpo mouse anti-human von Willebrand factor, se incubó por una hora y se lavó varias veces con PBS. Luego, se incubó con el anticuerpo secundario peroxidase conjugated goat anti-mouse immunoglobulin por 30 minutos, se lavó con PBS y se incubó con el sustrato de la enzima por 5 minutos. Como tinción de contraste 
se empleó hematoxilina. Para controlar la especificidad de la tinción se incluyeron dos controles: un cultivo de células HUVEC al que no se le adicionó anticuerpo primario y un cultivo de fibroblastos, que no expresan el factor, con anticuerpos primario y secundario.

\section{Ensayos de detección de E. faecalis intracelular en células HUVEC}

El ensayo utilizado para la detección intracelular de E. faecalis se adaptó del procedimiento seguido en los experimentos de protección a antibióticos $(10,11)$. Se incubaron frascos $T$ de $12,5 \mathrm{~cm}^{2}$ con cultivos HUVEC confluentes con tripsina $0,25 \%$ por 20 minutos a $37^{\circ} \mathrm{C}$ en atmósfera húmeda con $5 \%$ de $\mathrm{CO}_{2}$. Se adicionó DMEM con suplemento de SFB al 10\% para neutralizar la enzima; se centrifugó y el sedimento obtenido se resuspendió en $1 \mathrm{ml}$ de medio DMEM con suplemento de SFB al $20 \%$ y se sembró en platos de cultivo de 24 pozos (Falcon), utilizando una densidad de siembra de $5 \times 10^{4}$ células por pozo. Los cultivos se incubaron por 24 horas o hasta alcanzar confluencia; luego, se lavaron tres veces con PBS; se adicionó medio RPMI sin suplemento y se incubaron por 3 horas en atmósfera húmeda con $5 \%$ de $\mathrm{CO}_{2}$.

Transcurrido este tiempo, se agregó el inóculo bacteriano en medio RPMI a los pozos, utilizando una multiplicidad de infección de 2.000 bacterias por célula endotelial; se incubaron por 2 horas; se retiró el medio y las células se lavaron tres veces con PBS. Luego, se adicionó medio RPMI con suplemento de gentamicina-penicilina ( $500 \mathrm{mg}-500$ UI) y se incubaron por 2 horas $\left(5 \%\right.$ de $\mathrm{CO}_{2}$ y temperatura de $37^{\circ} \mathrm{C}$ ) con el fin de matar las bacterias extracelulares y las adheridas a la cara externa de la membrana celular. Después de trnascurrido tiempo, los cultivos se lavaron con PBS, se lisaron con una solución de Tritón X-100 al $1 \%$ (Sigma) y se realizaron diluciones seriadas del lisado que se sembraron por extensión en cajas de agar $\mathrm{BHI}$, se incubaron y se realizó el conteo de UFC.

Paralelamente, se llevó a cabo un experimento en el cual la infección se hizo con E. coli DH5a,y se incluyó como control negativo. Los datos se presentan como porcentaje de invasión $=100 \mathrm{x}$
(UFC recuperadas/UFC del inóculo inicial). Para comprobar la muerte de las bacterias extracelulares se sembraron $50 \mu \mathrm{l}$ del sobrenadante de los cultivos tratados con la mezcla de antibióticos, se incubaron y se observaron para establecer la aparición de UFC en el agar.

\section{Microscopia óptica de la invasión de E. faecalis a células HUVEC}

Se hicieron pasajes de células HUVEC de cultivos confluentes en frascos T 12,5 a láminas de vidrio estériles con una densidad de $2 \times 10^{4}$ células por lámina y se incubaron en ambiente húmedo con $5 \%$ de $\mathrm{CO}_{2}$ y temperatura de $37^{\circ} \mathrm{C}$ por 24 horas. Después de la incubación, se lavaron tres veces con PBS, se agregó medio RPMI sin suplemento y se incubaron por 3 horas en las mismas condiciones; se adicionó el inóculo bacteriano en medio RPMI con una multiplicidad de infección de 2.000 y se incubaron por 2 horas. Después de la incubación, se retiró el medio, se lavaron tres veces las células con PBS, se adicionó medio RPMI con suplemento de gentamicina-penicilina (500 mg-500 UI) y se incubó por 2 horas en 5\% de $\mathrm{CO}_{2}$ y $37^{\circ} \mathrm{C}$.

En este experimento se incluyeron cultivos infectados con la cepa de E. coli DH5a, como control negativo de la infección. Las láminas con los cultivos infectados se fijaron en metanol absoluto (Merck), se tiñeron con Gram o Giemsa y se observaron al microscopio.

\section{Microscopia electrónica de la invasión de E. faecalis a células HUVEC}

Se prepararon e infectaron cultivos en láminas de vidrio estériles de la forma descrita en los ensayos de microscopia óptica. Los cultivos infectados se fijaron en glutaraldehído al $3 \%$ en PBS (v/v) (Eufar), y se posfijaron con tetróxido de osmio; se sometieron a deshidratación en series ascendentes de etanol, embebidos en Epón, cortados finamente con un ultramicrótomo (LKBPharmacia), teñidos con una solución acuosa saturada de acetato de uranilo y citrato de plomo.

Las observaciones de los cortes se hicieron en un microscopio electrónico Phillips CM10 a 21.000 y 28.500 aumentos. 


\section{Resultados}

\section{Aislamiento y cultivo de células endoteliales de vena umbilical humana (HUVEC)}

En este trabajo encontramos que la digestión enzimática con tripsina de la lámina endotelial que recubre la vena del cordón umbilical humano y la agrupación de los productos digeridos provenientes de tres cordones umbilicales cada uno con longitudes aproximadas de $15 \mathrm{~cm}$ permiten establecer cultivos primarios HUVEC. En este paso, no se establece el número exacto de células endoteliales aisladas y sembradas por frasco T25 debido a que se obtienen muchos agregados celulares lo cual hace muy inexacto el conteo. Establecido el cultivo, los subcultivos se hacen con densidades celulares de $5 \times 10^{4}$ células por $\mathrm{cm}^{2}$.

En el panel A de la figura 1 se muestra un cultivo incubado por una semana, en el que se destaca la presencia de células con morfología poliédrica semejante a la reportada para el endotelio (18). El panel B corresponde a un cultivo con el mismo tiempo de incubación que fue sometido a tinción inmunohistoquímica para detectar la expresión del factor von Willebrand.

\section{Interacción de las células HUVEC con Enterococcus faecalis}

La presencia de bacterias viables dentro de las células endoteliales se estableció mediante un ensayo de protección a antibióticos. En éstos, después de infectar los cultivos con los aislamientos por dos horas, se adicionó una mezcla antibiótica de gentamicina y penicilina para matar las bacterias extracelulares, cuya muerte se comprobó mediante la siembra del sobranadante. Los tiempos de infección y el tamaño del inóculo utilizados se determinaron en experimentos preliminares. Se escogió en 2 horas el tiempo de incubación con las bacterias, debido a la excesiva acidificación del medio de cultivo observada después de las 4 horas. Se observó la presencia de UFC en el sembrado obtenido a partir del lisado celular luego de 2 horas de incubación en medio sin suplemento y 2 horas más en medio con suplemento con concentraciones bactericidas de gentamicina- penicilina. Los resultados de los conteos de UFC, expresados como porcentajes de invasión, fueron de $0,18 \%$ para el aislamiento enterocóccico Ef 2890 y de 0\% para la cepa de E. coli $\mathrm{DH} 5 \mathrm{a}$, usada como control negativo de la invasión.

\section{Ensayos con microscopia de luz}

El panel A de la figura 2 presenta cultivos endoteliales infectados con E. faecalis Ef 2890 teñidos con la coloración de Gram; el panel B, los cultivos sometidos a la tinción de Giemsa. En todos los casos se evidenció la asociación de los enterococos con las células HUVEC. Los
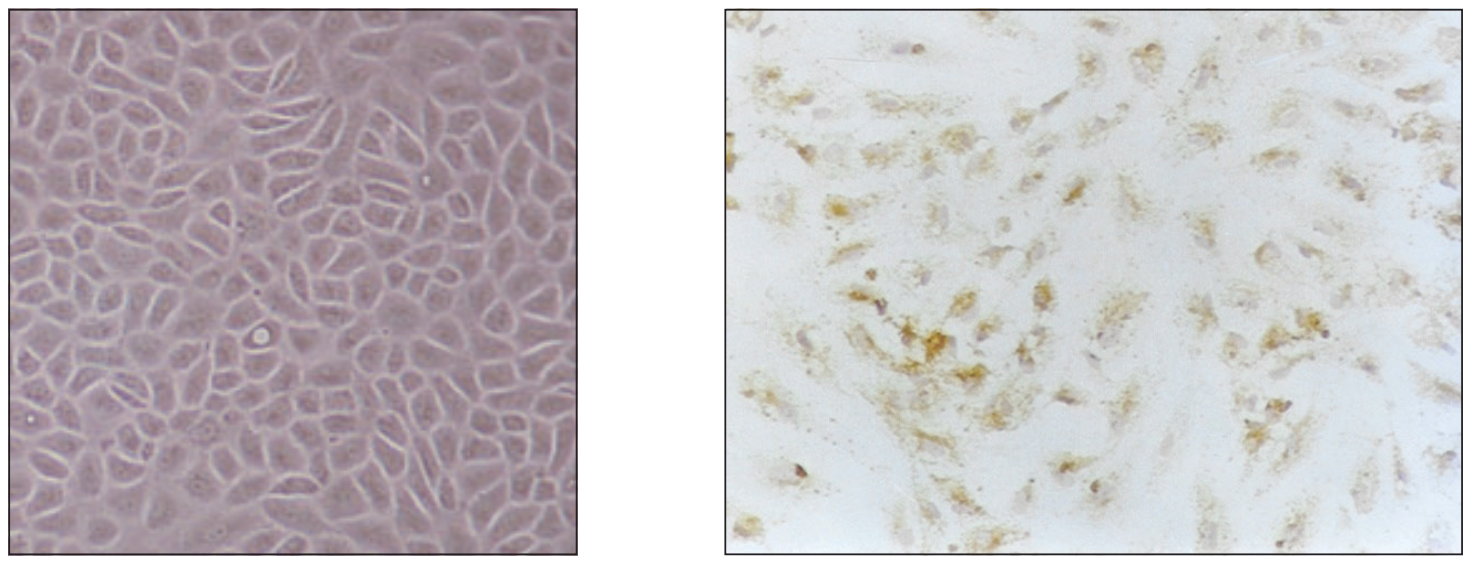

Figura 1. Cultivos confluentes de células HUVEC. A. Microscopía con contraste de fase; se observan células con uniones estrechas y morfología poliédrica que exhiben una organización en "empedrado". B. Tinción inmunohistoquímica positiva para la expresión de factor de von Willebrand. 

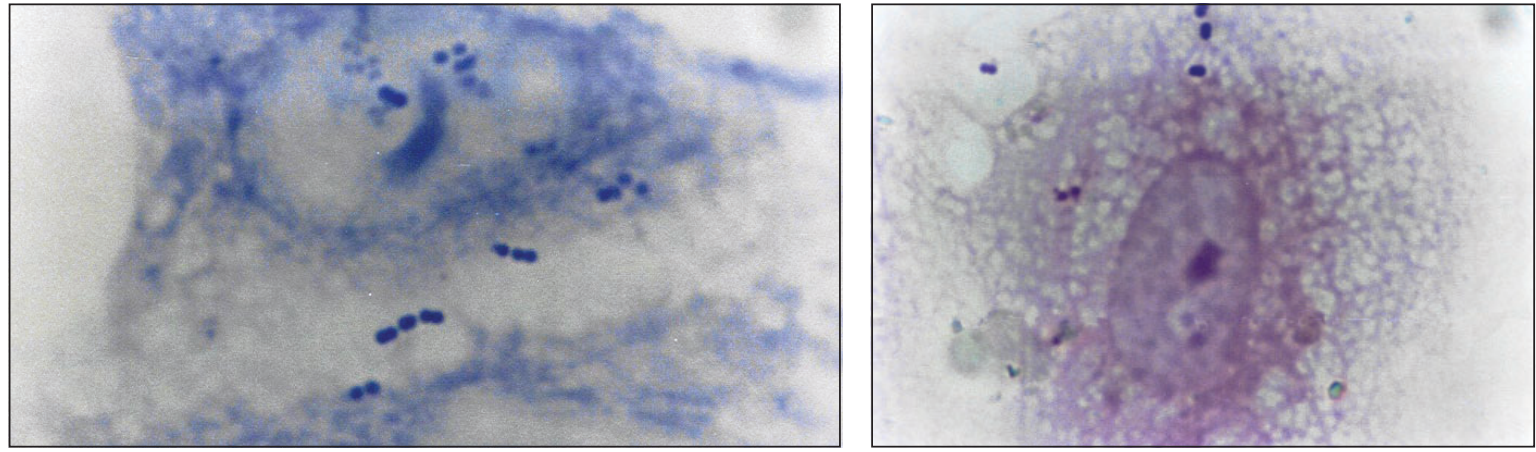

Figura 2. Microscopia óptica de la invasión de E. faecalis 2890 a células HUVEC. Los cultivos infectados se tiñeron con (A) Giemsa y (B) Gram y se observaron al microscopio. Las flechas señalan múltiples bacterias intracelulares (de acuerdo con los resultados del ensayo de protección a antibióticos), algunas en cadenas. E. faecalis 2890, 100X.

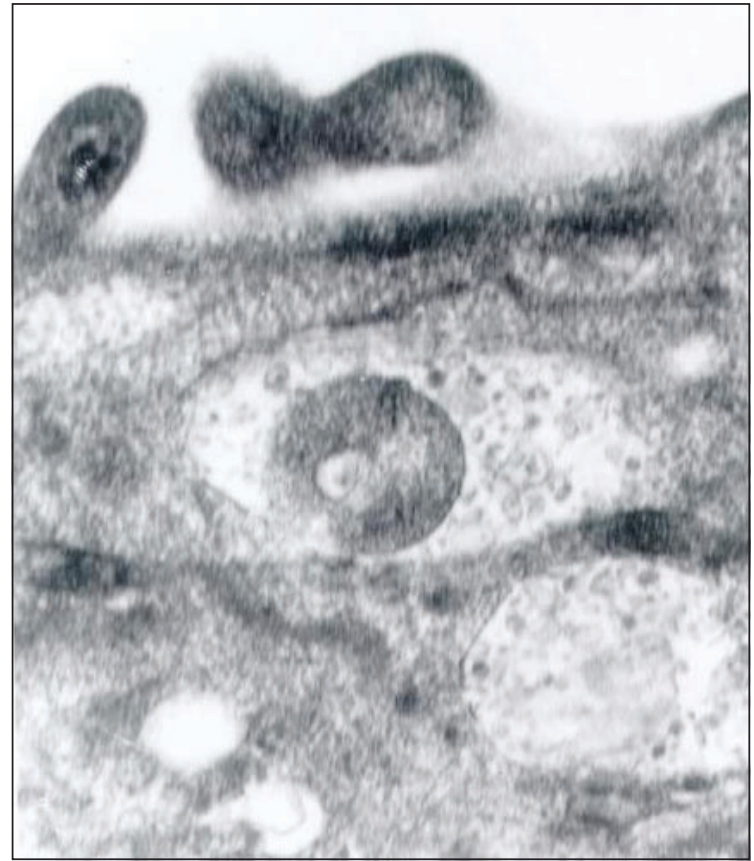

resultados de los tres experimentos realizados por triplicado indican que el aislamiento de E. faecalis Ef 2890 se asoció con $69,23 \%$ de las células endoteliales, mientras que la cepa de E. coli no estableció interacciones con éstas.

\section{Ensayos con microscopía electrónica de transmisión}

La microscopía electrónica de transmisión de células HUVEC inoculadas con E. faecalis 2890 (figura 3) muestra cocos intracelulares, algunos en vacuolas espaciosas $(A)$ otros en vacuolas

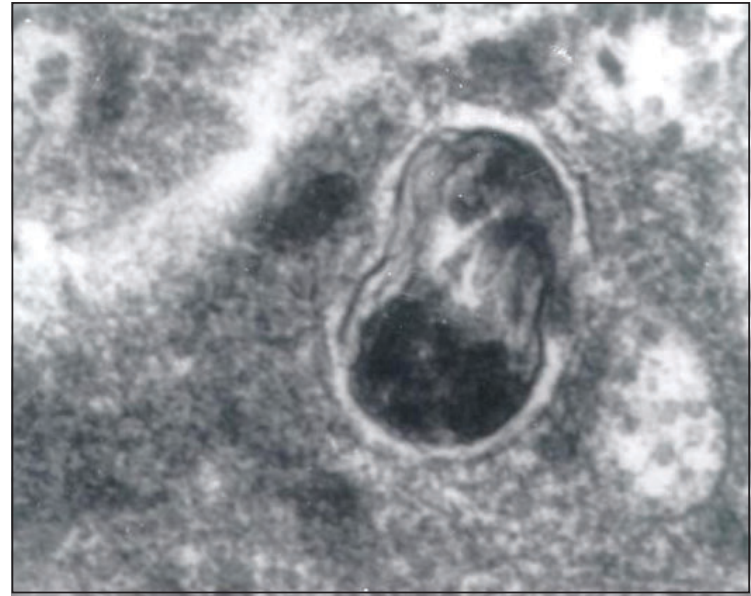

Figura 3. Microscopia electrónica de transmisión de la invasión de E. faecalis 2890 a células HUVEC. Se observan cocos intracelulares, algunos en vacuolas espaciosas (A, 21.000X) otros en vacuolas que se conforman al tamaño de la célula y en aparente división ( $\mathrm{B}, 28.500 \mathrm{X})$.

ajustadas al tamaño de la célula (B). En algunos casos se observan bacterias en división (B) y formando tabiques.

\section{Discusión}

La investigación detallada de la interacción que establecen las bacterias de la especie $E$. faecalis con las células endoteliales se ve favorecida por la posibilidad de establecer cultivos primarios con células endoteliales provenientes de la vena del cordón umbilical humano. Éstos, al formar una monocapa uniforme, proveen un buen sustrato para 
el estudio detallado de las interacciones bacteriacélula, y simulan la superficie encontrada in vivo por las bacterias que producen endocarditis (19). Aunque este sistema biológico ha sido utilizado para estudiar la invasión-ingreso de Staphylococcus aureus por medio de la célula endotelial $(19,21)$, no se ha aplicado para analizar las interacciones E. faecalis-endotelio.

A pesar de que las células endoteliales no son células fagocíticas profesionales, su capacidad para fagocitar in vitro las bacterias de la especie $S$. aureus ya ha sido descrita (19-21). La novedad de nuestro trabajo radica en que muestra la presencia intracelular de E. faecalis Ef 2890 en los cultivos primarios de HUVEC inoculados con esta bacteria. Las bacterias se observaron dentro de vacuolas endocíticas, algunas empezando a formar tabiques. En los modelos similares de infección con $S$. aureus se ha postulado que la presencia intracelular de estas bacterias puede ser un elemento clave en la génesis de las vegetaciones en las válvulas sanas (7,19-21). Una posible inferencia surgida de relacionar nuestros resultados con los obtenidos con $S$. aureus es que puede estar ocurriendo este mismo fenómeno in vivo con $E$. faecalis. Si éste es el caso, las bacterias estarían entrando a un ambiente intracelular protegido, reproduciéndose y, tal vez, pasando a través de la barrera endotelial.

Un estudio reciente mostró la presencia en sangre, hígado, riñón, corazón y bazo de dos cepas de $E$. faecalis inoculadas endovenosamente en un modelo en ratón (22). Los autores sugirieron que la gravedad de las lesiones histopatológicas causadas por la cepa más virulenta podía deberse a su habilidad de cruzar la barrera endotelial. La presencia de bacterias en vesículas endocíticas intracelulares detectada por nosotros puede ayudar a insinuar la hipótesis de que $E$. faecalis utiliza un mecanismo de transcitosis bacteriana para atravesar la lámina endotelial y causar daño tisular. Aunque el promedio del porcentaje de invasión $(0,18 \%)$ obtenido in vitro es bajo, puede tener significado biológico. Se ha reportado por otros autores que los porcentajes de invasión menores de 1 pueden llegar a ser importantes en un escenario in vivo (12).
Los resultados de este trabajo señalan que el modelo desarrollado basado en cultivos primarios de HUVEC puede ser una herramienta útil en el estudio de los mecanismos de patogenicidad que subyacen las patologías infecciosas del endotelio causadas por E. faecalis. En nuestro grupo, actualmente se están llevando a cabo experimentos tendientes a establecer el papel que la célula endotelial y la bacteria tienen en la invasión-ingreso descritos. Con ellos se espera esclarecer si la presencia intracelular de enterococos es debida a procesos de fagocitosis exhibidos por la célula endotelial en respuesta a los factores inductores producidos por la bacteria.

\section{Agradecimientos}

Este trabajo fue financiado parcialmente por el Instituto Colombiano para el Desarrollo de la Ciencia y la Tecnología Francisco José de Caldas, Colciencias, proyecto número 13080412635. Los autores quieren expresar su agradecimiento al Instituto de Genética Molecular Bacteriana de la Universidad El Bosque por facilitarnos la cepa $E$. faecalis 2890 y a María Mercedes Posada por la lectura crítica del documento.

\section{Referencias}

1. Morrison AJ Jr, Wenzel RP. Nosocomial urinary tract infections due to Enterococcus. Ten years' experience at a university hospital. Arch Intern Med 1986;146:154951.

2. Malathum K, Murray BE. Vancomycin-resistant enterococci: recent advances in genetics, epidemiology and therapeutic options. Drug Resist Update 1999;2:224-43.

3. Murray BE. The life and times of the Enterococcus. Clin Microbiol Rev 1990;3:46-65.

4. Panesso D, Ospina S, Robledo J, Vela MC, Peña J, Hernández 0 , Reyes J, Mejía G. Arias C. First characterization of cluster of VanA glycopeptideresistant Enterococcus faecium in a Colombian Hospital. Emerg Infect Dis 2002;8:961-5.

5. Arias CA, Reyes J, Zúñiga M, Cortés L, Cruz C, Rico CL, Panesso D. Multicentre surveillance of antimicrobial resistance in enterococci and staphylococci from Colombian hospitals, 2001-2002. J Antimicrob Chemother 2003;51:59-68.

6. McCormick JK, Tripp TJ, Dunny GM, Schlievert PM. Formation of vegetations during Infective endocarditis excludes binding of bacterial-specific host antibodies to Enterococcus faecalis. J Infect Dis 2002;185:994-7. 
7. Beekhuizen $\mathbf{H}$, van Furth $\mathbf{R}$. Growth characteristics of cultured human macrovascular venous and arterial and microvascular endothelial cells. J Vasc Res 1994; 31:230-9.

8. Srisatjaluk R, Kotwal GJ, Hunt LA, Justus DE. Modulation of gamma interferon-induced major histocompatibility complex class II gene expression by Porphyromonas gingivalis. Infect Immun 2002;70:118592.

9. Noel RF, Sato TT, Mendez C, Johnson MC, Pohlman TH. Activation of human endothelial cells by viable or heat-killed Gram-negative bacteria requires soluble CD14. Infect Immun1995;63:4046-53.

10. Drevets DA. Listeria monocytogenes infection of cultured endothelial cells stimulates neutrophil adhesion and adhesion molecule expression. J Immunol 1997; 158:5305-13.

11. Drevets DA, Sawyer RT, Potter TA, Campbell PA. Listeria monocytogenes infects human endothelial cells by two distinct mechanisms. Infect Immun 1995;63: 4268-76.

12. Wells CL, Jechorek RP, Erlandsen SL. Evidence for translocation of Enterococcus faecalis across the mouse intestinal tract. J Infect Dis 1990;162:82-90.

13. Wells CL, Maddaus MA, Simmons RL. Proposed mechanism for the translocation of intestinal bacteria. Rev Infect Dis 1988;10:958-76.

14. Wells CL, Moore EA, Hoag JA, Hirt H, Dunny GM, Erlandsen SL. Inducible expression of aggregation substance surface protein facilitates bacterial internalization by cultured enterocytes. Infect Immun 2000;68:7190-4.
15. Gentry-Weeks CR, Karkhoff-Schweizer R, Pikis A, Keith J. Survival of Enterococcus faecalis in mouse peritoneal macrophages. Infect Immun 1999;67:2160-5.

16. Sübmuth SD, Muscholl-Silberhorn A, Wirth R, Susa M, Marre R, Rozdzinski E. Aggregation substance promotes adherence, phagocytosis, and intracellular survival of Enterococcus faecalis within human macrophages and suppresses respiratory burst. Infect Immun 2000;68:4900-6.

17. Bertuccini L, Ammendolia MG, Superti F, Baldassarri L. Invasión of HeLa cells by Enterococcus faecalis clinical isolates. Med Microbiol Immunol 2002; 191:25-31.

18. Jaffe EA, Nachman RL, Becker CG, Minick CR. Culture of human endothelial cells derived from umbilical veins. Identification by morphologic and immunologic criteria. J Clin Invest 1973;52:2745-56.

19. Ogawa SK, Yurberg ER, Hatcher VB, Levitt MA, Lowy FD. Bacterial adherence to human endothelial cells in vitro. Infect Immun 1985;50:218-24.

20. Hamill RJ, Vann JM, Proctor RA. Phagocytosis of Staphylococcus aureus by cultured bovine aortic endothelial cells: model for postadherence events in endovascular infections. Infect Immun 1986;54:833-6.

21. Vann JM, Proctor RA. Ingestion of Staphylococcus aureus by bovine endothelial cells results in time- and inoculum-dependent damage to endothelial cell monolayers. Infect Immun 1987;55:2155-63.

22. Gentry-Weeks CR, Estay M, Loui C, Baker D. Intravenous mouse infection model for studying the pathology of Enterococcus faecalis infections. Infect Immun 2003;71:1434-41. 